\title{
IDENTIFIKASI KEANEKARAGAMAN HAYATI RTH DI KOTA DEPOK
}

\author{
Ray March Syahadat ${ }^{1,{ }^{*}}$, Priambudi Trie Putra ${ }^{1}$, Pitria Ramadanti ${ }^{1}$, Daisy Radnawati ${ }^{1}$, \\ Siti Nurisjah ${ }^{2}$ \\ ${ }^{1}$ Program Studi Arsitektur Lanskap, Fakultas Teknik Sipil dan Perencanaan, Institut Sains dan \\ Teknologi Nasional, Jl. Moh. Kahfi II Srengseng Sawah, Jagakarsa, Jakarta Selatan, 12640 \\ ${ }^{2}$ Ikatan Arsitektur Lansekap Indonesia, Jakarta Design Center, Jakarta, 10260 \\ *ray.arl@istn.ac.id
}

\begin{abstract}
ABSTRAK. Pembangunan perkotaan tidak hanya harus terfokus pada lanskap binaan tetapi juga pada lanskap alami. Salah satu elemen lunak yang dianggap penting yaitu keberadaan ruang terbuka hijau (RTH). Pengembangan RTH di lanskap perkotaan selama ini umumnya lebih terfokus dalam mencapai tujuan mereduksi polutan, menciptakan kenyamanan termal, dan juga estetika. Sayangnya, masih banyak yang mengabaikan manfaat RTH dari sudut pandang konservasi khususnya flora dan fauna. Studi ini bertujuan untuk mendata keanekaragaman hayati di Kota Depok untuk menjadi acuan dalam mencapai pembangunan berkelanjutan (green development), sehingga kualitas lingkungan dapat ditingkatkan dan fungsional bukan hanya bagi manusia tetapi juga bagi flora dan fauna. Studi dilaksanakan di tiga lokasi dengan karakter yang berbeda yaitu Taman Lembah Gurame, Tahura Pancoran Mas, dan Jalan Juanda. Hasil yang diperoleh nilai keanekaragaman vegetasi berturut-turut berada pada Tahura Pancoran Mas $(2,535)$, Taman Lembah Gurame $(1,287)$, dan Jalan Juanda $(0,967)$. RTH di Jalan Juanda merupakan RTH dengan nilai keanekaragaman vegetasi paling rendah. Rendahnya nilai keanekaragaman vegetasi berpengaruh langsung terhadap keberadaan fauna yang tidak ditemukan pada RTH Jalan Juanda. Studi ini juga berhasil mendata vegetasi-vegetasi penting pada tiap-tiap lokasi yang dapat memberikan informasi mengenai mampu tidaknya vegetasi tersebut beradaptasi dengan lingkungannya.
\end{abstract}

Kata kunci: fauna, flora, konservasi, lanskap perkotaan, ruang terbuka hijau.

ABSTRACT. Urban development should not only focus on the man-made landscape but also the natural landscape. One of the important natural landscape is the existence of green open space. Green open space development in urban landscape areas has generally been more focused on achieving the goal of reducing pollutants, creating thermal comfort, as well as aesthetics. Unfortunately, the benefits of green space from the conservation, especially for flora and fauna are still largely ignored. This study aims to record biodiversity in Depok City to become a reference in achieving sustainable development (green development), so that environmental quality can be improved and functional not only for human but also for flora and fauna. The study was conducted in three locations with different characters namely Taman Lembah Gurame, Tahura Pancoran Mas, and Jalan Juanda. The results obtained by the value of vegetation diversity are consecutively in Tahura Pancoran Mas (2,535), Lembah Gurame Park (1,287), and Jalan Juanda (0.967). Green open space on Jalan Juanda has the lowest value of vegetation diversity. The low value of vegetation diversity directly affects the presence of fauna because not found in the Jalan Juanda. This study also managed to record important vegetations in each location that can provide information for whether or not the vegetation well-adapted in its environment.

Keywords: conservation, fauna, flora, green open space, urban landscape

\section{PENDAHULUAN}

Kota identik dengan dominasi elemen arsitektural seperti beton, kaca, dan perkerasan lain sebagai wilayah yang kegiatan utamanya bukan kegiatan pertanian [1][2]. Berbeda dengan pedesaan, kota berfokus pada kegiatan perekonomian dari sektor jasa, pemerintahan, dan pelayanan sosial. Sebagian besar masyarakat dunia saat ini bertempat tinggal di perkotaan karena kegiatan ekonomi cenderung terpusat di kawasan perkotaan. Implikasi dari kegiatan ekonomi yang terpusat di perkotaan adalah tingkat pertumbuhan penduduk yang semakin tinggi. Hal ini memicu terjadinya kegiatan pembangunan fisik di perkotaan untuk alasan memenuhi kebutuhan manusia. Beberapa contoh pembangunan fisik di perkotaan yaitu berupa pembangunan perumahan, fasilitas pendidikan, gedunggedung perkantoran, kawasan perdagangan, pelabuhan/bandara, serta jaringan jalan. Semua pembangunan fisik ternyata berdampak negatif bagi keberlanjutan kota. Berkurangnya lahan perkotaan sebagai konsekuensi logis pembangunan fisik 
perkotaan yang sulit dielakkan. Proporsi ruang terbuka hijau (RTH) kota yang tidak ideal adalah salah satu dampak dari pembangunan fisik perkotaan.

Salah satu indikator kota yang berkelanjutan dapat ditinjau dari ketersediaan RTH. Kota yang memiliki ketersediaan RTH yang cukup akan mampu menjaga keberlanjutan kota. RTH perkotaan menjadi ruang alami bagi kehidupan flora maupun fauna kota sehingga keberadaan mereka tetap lestari. RTH perkotaan yang terjaga proporsi luasnya akan mampu menjamin ketersediaan air melalui kemampuan tanah untuk menyerap air hujan serta badan air yang berada di atasnya. RTH perkotaan juga berfungsi memberikan suplai udara bersih sehingga menyehatkan warga kota.

Kegiatan penghijauan yang dilakukan di perkotaan saat ini, atau juga dikenal dengan istilah pemanfaatan untuk RTH, sering didominasi dengan kegiatan untuk penutupan lahan dengan fungsi arsitektural dan keindahannya saja. Pada kenyataannya, fungsi-fungsi tersebut sudah berjalan dan terlihat dengan baik. Tetapi berbagai jenis vegetasi dan tanaman yang ditanam dalam wilayah perkotaan, pada lokasi atau kawasan yang sama, juga harus ditujukan untuk memberikan fungsi dan manfaat yang tinggi untuk peningkatan kualitas dan keindahan lingkungannya. Tidak hanya memiliki fungsi dan manfaat, vegetasi dengan kriteria signifikansi tertentu juga dapat menjadi vegetasi pusaka [3][4][5]. Jenis-jenis tanaman yang berada dalam pertamanan dan RTH kota tak hanya merupakan kelompok tanaman yang indah tetapi juga dapat bermanfaat secara ekologis [6]. Salah satu manfaat ekologis dari tanaman adalah sebagai relung dan habitat satwa liar.

Keberadaan ruang hijau di perkotaan yang lestari menjadi penting sebagai sumber data untuk mengkaji keanekaragaman hayati, baik flora maupun fauna, yang berada di kota tersebut. Permen Lingkungan Hidup No. 29 Tahun 2009 mensyaratkan bahwa setiap kota memerlukan data untuk keanekaragaman hayati. Pendataan diperlukan untuk mengetahui jenis-jenis flora maupun fauna yang dipertahankan sehingga pihak-pihak yang terkait dengan pengambil kebijakan perkotaan dapat lebih berhati-hati dalam merencanakan ruang-ruang perkotaan pada masa yang akan datang.

Kota Depok merupakan kota yang terletak di selatan Kota Jakarta. Kota Depok awalnya merupakan bagian dari wilayah Kabupaten Bogor dan berstatus kota administratif. Sejak menjadi kota mandiri pada 1999, Kota Depok semakin berkembang menjadi kota penyangga Jakarta. Harga tanah yang dianggap relatif lebih terjangkau, lingkungan yang masih asri, serta akses yang dekat dengan Jakarta menjadikan Kota Depok memiliki magnet bagi berkembangnya permukiman, kegiatan pendidikan, serta aktivitas perdagangan. Infrastruktur di Kota Depok juga selalu berkembang seiring dengan tingginya kebutuhan masyarakat. Kota Depok jika ditinjau dari PP RI No. 34 Tahun 2009 termasuk dalam kota metropolitan karena Kota Depok memiliki penduduk di atas satu juta jiwa, memiliki dominasi fungsi sebagai kota jasa, perdagangan, dan industri, dengan jangkauan antarprovinsi maupun nasional.

Semua hal tersebut memberikan permasalahan baru bagi keberlanjutan Kota Depok, yaitu permasalahan tata ruang. Tata ruang yang bermasalah akan berdampak bagi keberadaan RTH yang ada di Kota Depok. Apabila RTH Kota Depok rusak atau menghilang akibat pembangunan kota yang tidak hati-hati, akan berdampak buruk bagi keanekaraman hayati yang terdapat di Kota Depok. Perlu kehati-hatian dalam mengambil arah kebijakan pembangunan agar ruangruang alami perkotaan dapat lestari, berdaya guna, dan berhasil guna.

Dalam rangka peningkatan kualitas lingkungan Kota Depok melalui penghijauan yang fungsional maka akan dilakukan pendataan keanekaragam hayati atau pendataan flora dan fauna dalam wilayah Kota Depok. Diharapkan hasil pendataan dapat menjadi database (data dasar) untuk berbagai model pembangunan yang berwawasan lingkungan (green development) dan kontekstual di Kota Depok.

\section{METODE PENELITIAN}

Kajian pendataan keanekaragaman hayati dilakukan di ruang-ruang terbuka publik khususnya di Taman Lembah Gurame (Gambar 1), Tahura Pancoran Mas (Gambar 2), dan Jalan Juanda (Gambar 3). Ketiga lokasi ini dipilih untuk mewakili tiga bentuk patch, yaitu patch berbentuk irregular (Taman Lembah Gurame), persegi (Tahura Pancoran Mas), dan garis (Jalan Juanda). Hal yang mendasari pemilihan tiga bentuk patch tersebut adalah perbedaan bentuk patch akan mempengaruhi keanekaragaman. Bentuk patch menjadi pertimbangan sebab sebagai struktur ekologi lanskap memiliki pengaruh 
terhadap keanekaragaman. Penelitian yang dilakukan Wardiningsih et al. Juga melaporkan bahwa patch juga memiliki pengaruh terhadap kualitas visual lanskap [7]. Ketiga lokasi tersebut juga mewakili tiga karakter yaitu 1) Taman Lembah Gurame sebagai representasi taman kota yang relatif lengkap (ragam vegetasi dan memiliki badan air), 2) Tahura Pancoran Mas sebagai salah satu cagar alam tertua di Indonesia yang kini statusnya diturunkan menjadi tahura, dan 3) Jalan Juanda sebagai RTH berbentuk koridor atau jalur.

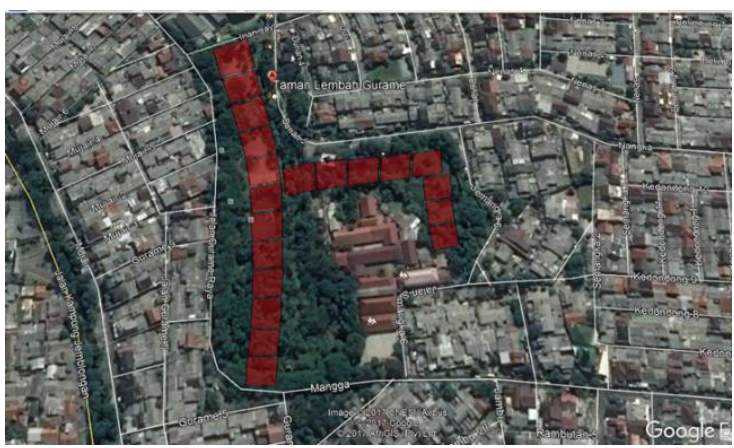

Gambar 1. Peta pengambilan sampel Taman Lembah Gurame

(Sumber: Google Earth, 2017)

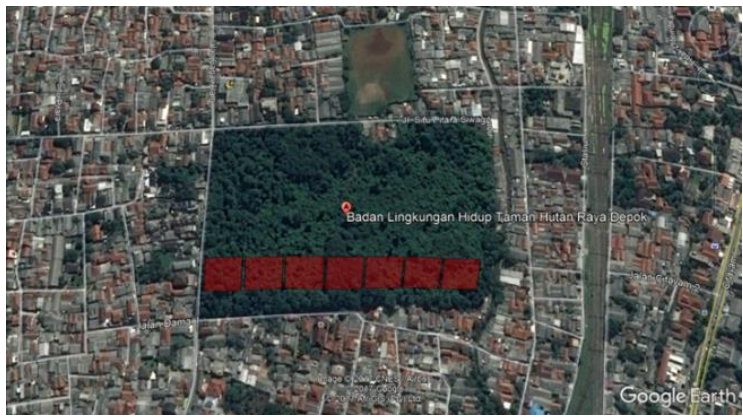

Gambar 2. Peta pengambilan sampel Tahura Pancoran Mas

(Sumber: Google Earth, 2017)

Data yang akan dikumpulkan adalah data vegetasi dan satwa liar, dan kondisi lingkungan pembentuk taman yang diamati. Pengumpulan data dan informasi dilakukan secara primer yaitu melalui pengamatan langsung di lapangan dan mewawancara masyarakat setempat; dan data sekunder dikumpulkan melalui studi pustaka dan bahanbahan yang sudah dipublikasi.

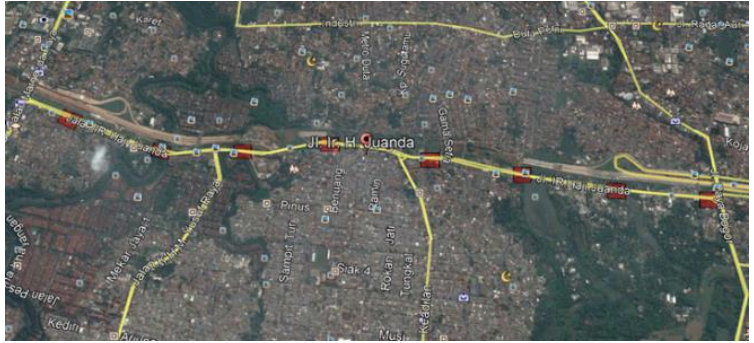

Gambar 3. Peta pengambilan sampel Jalan Juanda (Sumber: Google Earth, 2017)

Dalam proses analisis ini akan digunakan metode analisis yang sesuai dengan jenis dan tujuan kajian yaitu deskriptif. Selain itu dilibatkan pula pihak yang kompeten seperti tenaga ahli/pakar sehingga didapat hasil analisis yang lebih komprehensif. Vegetasi pada tiga tempat didata dengan mengacu pada mengacu pada Alfian et al. yang menggunakan metode kuadran dengan ukuran $20 \times 20 \mathrm{~m}^{2}$ sebagai petak [8]. Menurut Putrawan cara ini baik digunakan pada lokasi yang terdapat gradasi perubahan lingkungan [9]. Adapun data yang dikumpulkan dalam inventarisasi keanekaragaman vegetasi yaitu nama spesies tanaman, keliling batang, jari-jari batang, diameter batang, tinggi tanaman, dan luas tajuk.

Selanjutnya dilakukan analisis struktur dan komposisi jenis vegetasi dengan menghitung dominansi, dominansi relatif, frekuensi, frekuensi relatif, dan kerapatan pada setiap taman. Adapun formula yang digunakan yaitu sebagai berikut:

1. Dominansi

Dominansi $=\frac{\text { luas seluruh } k a n o p i}{\text { luas proyeksi petak }}$

2. Dominansi relatif

$D r=\frac{D s}{D t s} \times 100 \%$

Keterangan:

$\mathrm{Dr}=$ Dominansi relatif

Ds = Dominansi spesies

Dts = Dominansi total spesies

3. Frekuensi

$F=\frac{\text { Jumlah petak terisi suatu spesies }}{\text { jumlah seluruh petak }}$

Keterangan:

$\mathrm{F} \quad=$ Frekuensi 
4. Frekuensi relatif

$F r=\frac{F s}{F t s} \times 100 \%$

Keterangan:

$\mathrm{Fr} \quad=$ Frekuensi relatif

Fs = Frekuensi spesies

Fts $=$ Frekuensi total spesies

5. Kerapatan

$K=\frac{\text { jumlah individu suatu spesies }}{\text { luas seluruh petak }}$

Keterangan:

$\mathrm{K}=$ Kerapatan

6. Kerapatan relatif

$K r=\frac{K s}{K t s} \times 100 \%$

Keterangan:

$\mathrm{Kr} \quad=$ Kerapatan relatif

$\mathrm{Ks}=$ Kerapatan spesies

Kts = Kerapatan total spesies

7. Indeks nilai penting

$I N P=F r+D r+K r$

Keterangan:

INP = Indeks nilai penting

$\mathrm{Fr} \quad=$ Frekuensi relatif

$\mathrm{Dr} \quad=$ Dominansi relatif

$\mathrm{Kr} \quad=$ Kerapatan relatif

Untuk pengukuran keragaman menggunakan metode Shanon-Wiener dengan formula sebagai berikut:

$H=-\sum P i \ln P i$

Keterangan

$\mathrm{H}=$ Indeks keragaman Shanon-Wiener

$\mathrm{Pi} \quad=$ Jumlah individu spesies per jumlah total seluruh spesies

Adapun formula untuk menghitung jumlah spesies per jumlah adalah sebagai berikut:

$P i=N i / N$ total

Keterangan

$\mathrm{Pi} \quad=$ Jumlah individu spesies per jumlah total seluruh spesies

$\mathrm{Ni}=$ Jumlah individu spesies $\mathrm{i}$

$\mathrm{N}$ total = Jumlah total individu
Nilai indeks keragaman $\mathrm{H}<1$ menunjukkan keragaman spesies yang rendah. Jika indeks keragaman sebesar $1 \leq \mathrm{H} \leq 3$ menunjukkan keragaman spesies sedang. Selanjutnya indeks keragaman sebesar $\mathrm{H}>3$, bermakna keragaman spesies yang tinggi.

Untuk identifikasi satwa dilakukan dengan metode wawancara kepada 30 responden per masing-masing area sehingga total responden yang dikumpulkan sebesar 90 orang responden. Responden yang dipilih merupakan responden yang berada di sekitar lokasi. Hal ini dimaksudkan agar informasi yang diperoleh benar dapat dipercaya karena responden dalam kesehariannya berada di sekitar tapak.

\section{HASIL DAN PEMBAHASAN}

\section{Keanekaragaman Taman Lembah Gurame}

Taman Lembah Gurame merupakan salah satu taman kota yang terdapat di Kota Depok yang memiliki luas 3 ha. Taman ini terletak di Jalan Gurame Raya, Kecamatan Pancoran Mas, Kota Depok. Taman Lembah Gurame dibangun untuk memenuhi target kebutuhan RTH minimal perkotaan, sesuai UU No. 26 Tahun 2007, sebesar tiga puluh persen. Taman Lembah Gurame ini dibangun pada akhir tahun 2012. Keberadaan kolam-kolam air di dalam taman menjadi bukti bahwa kawasan ini memang merupakan areal resapan air. Areal Taman Lembah Gurame pernah difungsikan sebagai tempat pembuangan sampah serta banyak dijumpai bangunan liar. Saat ini, Taman Lembah Gurame difungsikan sebagai area aktivitas warga serta ruang untuk berinteraksi.

Berdasarkan hasil pengamatan di lokasi terdapat 77 spesies dengan total individu sebesar 1112 vegetasi pada petak pengambilan sampel (Gambar 4). Bentuk patch yang irregular menyebabkan banyaknya edges sehingga memiliki implikasi yang cukup tinggi untuk penyebaran spesies.

Kerapatan suatu spesies menggambarkan jumlah spesies pada lokasi pengamatan. Di taman Lembah Gurame, kerapatan tertinggi ditemukan pada spesies Arundinaria pumila sebesar 26,349\%. Frekuensi tertinggi pada Lembah Gurame juga terdapat pada vegetasi Arundinaria pumila dengan nilai sebesar $26,365 \%$ (Tabel 1). Hal ini dapat menjelaskan bahwa Arundinaria pumila merupakan jenis yang paling rapat dan selalu hampir ditemukan di Taman Lembah Gurame. 
Samanea saman merupakan vegetasi dengan dominansi tertinggi dengan persentase dominasi realatif sebesar $28,781 \%$ (Tabel 2). Artinya pada Taman Lembah Gurame terkonsentrasi pada spesies tersebut. Tabel 3 menunjukkan vegetasi dengan nilai INP tertinggi. Vegetasi dengan INP tertinggi yaitu Arundinaria pumila dengan nilai INP sebesar 54,142 diikuti oleh Samanea saman $(32,739)$ dan Spatodhea campanulata $(14,765)$. Sedangkan tanaman dengan INP paling rendah yaitu Lantana camara dengan INP sebesar $0,189 \% \quad$ (Tabel 4). Nilai INP menggambarkan peranan suatu spesies pada komunitasnya dalam hal ini Taman Lembah Gurame. Nilai ini diperoleh dari penjumlahan kerapatan, frekuensi, dan dominansi spesies. Selanjutnya nilai keanekaragaman spesies di Taman Lembah Gurame sebesar 1,287 yang artinya keanekaragaman spesies masuk dalam kategori sedang.

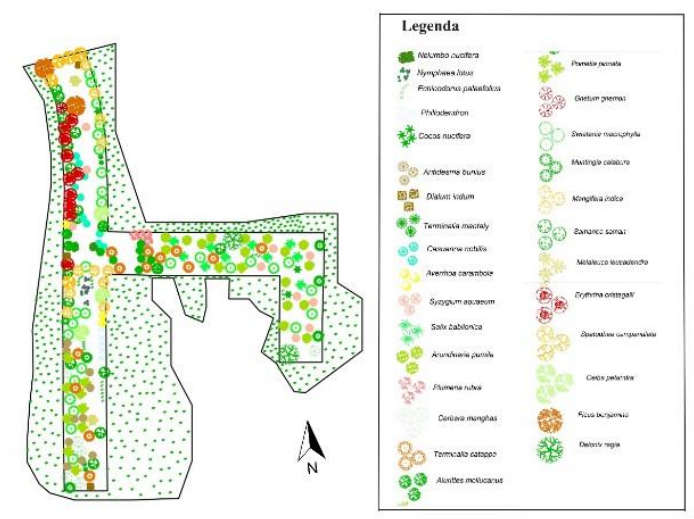

Gambar 4. Peta sebaran vegetasi pada tapak Taman Lembah Gurame

(Sumber: Hasil Pengolahan Data, 2017)

Berdasarkan hasil wawancara kepada responden di sekitar Taman Lembah Gurame, diperoleh informasi bahwa spesies satwa yang sering ditemukan di Taman Lembah Gurame antara lain kupu-kupu, kucing, ikan gurame, katak, ular, dan ikan mas koki. Satwa kupukupu paling sering ditemukan di area vegetasi yang memiliki fitur bunga.

\section{Keanekaragaman Tahura Pancoran Mas}

Taman Hutan Raya (Tahura) Pancoran Mas terletak di Jalan Cagar Alam, Pancoran Mas, Kota Depok. Berdasarkan PP No. 68 Tahun 1998, Tahura merupakan kawasan pelestarian alam untuk tujuan koleksi tumbuhan dan atau satwa yang alami atau bukan alami, jenis asli dan atau bukan asli, yang dimanfaatkan bagi kepentingan penelitian, ilmu pengetahuan, pendidikan, menunjang budidaya, budaya, pariwisata, dan rekreasi. Tahura Pancoran Mas saat ini memiliki luas 7,1 ha [10]. Tahura Pancoran Mas menjadi paru-paru Kota Depok karena adanya tegakan pepohonan yang mampu menyerap gas $\mathrm{CO}^{2}$ serta menjadi cadangan karbon. Selain itu, Tahura berfungsi sebagai ruang alami perkotaan yang menjaga keberlanjutan kota. Penelitian yang dilakukan oleh Mariski et al., Alfian et al., Desyana et al., dan Putra menyatakan bahwa keberadaan pepohonan di perkotaan selain memiliki manfaat mereduksi polutan, juga dapat menciptakan kenyamanan termal [8][11][12][13].

Tabel 1. Vegetasi dengan frekuensi relatif dan kerapatan relatif tertinggi di Taman Lembah

\begin{tabular}{lrr}
\multicolumn{3}{c}{ Gurame } \\
\hline Spesies & $\begin{array}{r}\text { Frekuensi } \\
\text { relatif }(\%)\end{array}$ & $\begin{array}{r}\text { Kerapatan } \\
\text { relatif }(\%)\end{array}$ \\
\hline Arundinaria pumila & 26,365 & 26,349 \\
$\begin{array}{l}\text { Ruellia } \\
\text { malacosperma }\end{array}$ & 7,199 & 7,194 \\
Swietenia & & \\
macrophylla & 4,409 & 4,406 \\
Mangifera indica & 3,869 & 3,867 \\
Nelumbo nucifera & 3,599 & 3,597 \\
Echinodorus & 3,239 & 3,237 \\
palaefolius & & \\
Cordyline sp. & 2,879 & 2,878 \\
Epipremum aureum & 2,430 & 2,428 \\
Thalia geniculata & 2,340 & 2,338 \\
Cyperus papyrus & 2,250 & 2,248 \\
Nymphaea lotus & 2,250 & 2,248 \\
\hline
\end{tabular}

Tabel 2. Vegetasi dengan dominansi relatif tertinggi di Taman Lembah Gurame

\begin{tabular}{lr}
\hline \multicolumn{1}{c}{ Spesies } & Dominansi Relatif (\%) \\
\hline Samanea saman & 28,781 \\
Spatodhea & 13,686 \\
campanulata & \\
Ceiba petandra & 11,213 \\
Ficus benjamina & 11,139 \\
Delonix regia & 4,878 \\
Swietenia macrophylla & 4,484 \\
Mangifera indica & 4,298 \\
Syzygium aqueum & 2,524 \\
Arthocarpus altilis & 2,064 \\
Arundinaria pumila & 1,429 \\
\hline
\end{tabular}

Tahura Pancoran Mas diduga merupakan bagian tanah milik pendiri Depok, yaitu Cornelis Chastelein dengan luas yang lebih 
besar daripada kondisi eksisting saat ini. Tahura ini merupakan representasi kondisi alam Kota Depok yang dulunya masih banyak memiliki hutan. Keberadaan Tahura Pancoran Mas menjadi penting karena potensi keanekaragaman hayati yang terkandung di dalamnya dapat menjadi sumber data sebagai acuan pembangunan berkelanjutan bagi Kota Depok.

Vegetasi yang terinventarisasi pada 7 petak sampel Tahura Pancoran Mas sebanyak 43 spesies dengan total jumlah individu sebanyak 409 individu (Gambar 5). Gigantochloa apus merupakan spesies dengan kerapatan tertinggi $(18,582 \%)$ kemudian disusul oleh Diefenbachia sp. (13,203\%). Data ini menggambarkan bahwa kedua spesies tersebut merupakan spesies yang yang memiliki kemampuan adaptasi yang baik di lingkungannya [14].

\begin{tabular}{lc}
\multicolumn{2}{c}{$\begin{array}{c}\text { Tabel 3. Vegetasi dengan indeks nilai penting } \\
\text { tertinggi di Taman Lembah Gurame }\end{array}$} \\
\multicolumn{1}{c}{ Spesies } & INP \\
\hline Arundinaria pumila & 54,142 \\
Samanea saman & 32,749 \\
Spatodhea campanulata & 14,775 \\
Ruellia malacosperma & 14,412 \\
Swietenia macrophylla & 13,309 \\
Ficus benjamina & 12,049 \\
Mangifera indica & 12,034 \\
Ceiba petandra & 11,933 \\
Nelumbo nucifera & 7,381 \\
Echinodorus palaefolius & 6,609
\end{tabular}

\begin{tabular}{lc}
\multicolumn{2}{c}{$\begin{array}{c}\text { Tabel 4. Vegetasi dengan indeks nilai penting } \\
\text { terendah di Taman Lembah Gurame }\end{array}$} \\
\hline \multicolumn{1}{c}{ Nama Spesies } & INP \\
\hline Lantana camara & 0,189 \\
Chrysalidocarpus lutescens & 0,214 \\
Ficus coreanus & 0,214 \\
Malaleuca leucadendra & 0,248 \\
Myristica fragrans & 0,248 \\
Ficus lyrata & 0,276 \\
Gnetum gnemon & 0,276 \\
Macarangan tanarius & 0,289 \\
Aleurittes mollucannus & 0,346 \\
Sandoricum koetjape & 0,379
\end{tabular}

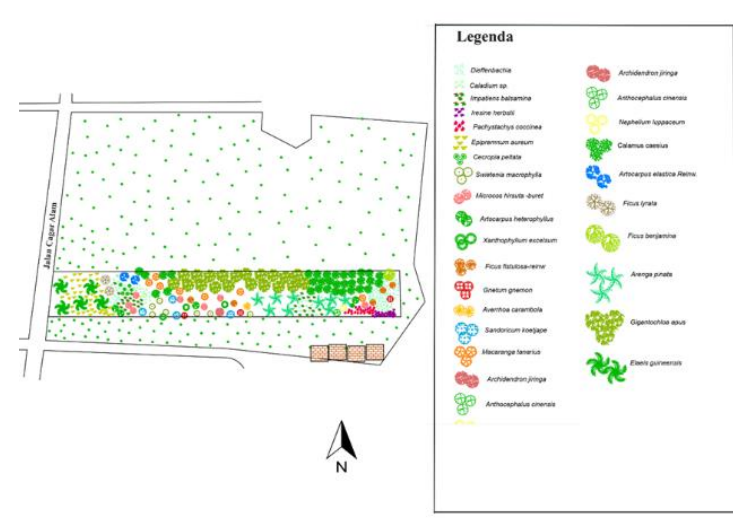

Gambar 5. Peta sebaran vegetasi pada tapak Tahura Pancoran Mas

(Sumber: Hasil Pengolahan Data, 2017)

Kedua spesies tersebut juga merupakan dua frekuensi tertinggi di Tahura Pancoran Mas (Tabel 5). Dominasi tertinggi Arenga pinnata dan Elais guineensis dengan nilai dominansi relatif masing-masing $30,252 \%$ dan $19,413 \%$ (Tabel 6). Nilai tersebut sesuai dengan fakta di lapangan karena paling banyak menempati ruang tumbuh terutama luas bidang dasar. Tabel 7 menunjukkan indeks nilai penting tertinggi di Tahura Pancoran Mas. Vegetasi dengan nilai INP tertinggi yaitu Gigantochloa apus $(39,332)$, Arenga pinnata $(36,609)$, Dieffenbachia sp. $(27,122)$, dan Elaeis guineensis $(21,369)$. Vegetasi-vegetasi tersebut berperan penting terhadap komunitasnya dalam hal ini stabilitas ekosistem. Gigantochloa apus dan Arenga pinnata merupakan salah satu indikator bahwa daerah tersebut memiliki kekayaan air. Hal ini sejalan dengan penelitian yang dilakukan Radnawati tentang hubungan keberadaan RTH dan konservasi air [15].

Hal yang menarik di sini adalah Depok selama ini dikenal sebagai kota belimbing. Namun dari hasil kajian di Tahura Pancoran Mas indeks nilai penting belimbing hanya sekitar 0,549 (Tabel 8). Artinya vegetasi yang menjadi maskot kota ini malah masuk dalam kategori langka karena mempunyai nilai kerapatan, frekuensi, dan dominansi yang rendah. Nilai keanekaragaman di Tahura Pancoran Mas sebesar 2,535. Artinya keanekaragaman di Tahura Pancoran Mas dalam kategori sedang. Berdasarkan hasil wawancara, satwa yang dilaporkan oleh 30 responden antara lain ular weling, tupai bergaris, kupu-kupu, gagak, dan burung semak. 
Tabel 5. Vegetasi dengan frekuensi relatif dan kerapatan relatif tertinggi di Tahura Pancoran Mas

\begin{tabular}{lrr}
\hline \multicolumn{1}{c}{ Spesies } & $\begin{array}{r}\text { Kerapatan } \\
\text { relatif }(\%)\end{array}$ & $\begin{array}{r}\text { Frekuensi } \\
\text { relatif }(\%)\end{array}$ \\
\hline Gigantochloa apus & 18,582 & 18,582 \\
Dieffenbachia sp. & 13,203 & 13,203 \\
Selaginella doederleinii & 7,090 & 7,090 \\
Calamus caesius & 5,379 & 5,379 \\
Epipremnum aureum & 5,134 & 5,134 \\
Iresine herbstii & 4,890 & 4,890 \\
Pachystachys coccinea & 4,401 & 4,401 \\
Impatiens balsamina L. & 3,912 & 3,912 \\
Setaria plicata & 3,912 & 3,912 \\
Macarangan tanarius & 3,423 & 3,423 \\
Solanum nigrum & 3,423 & 3,423 \\
\hline
\end{tabular}

Tabel 6. Vegetasi dengan dominansi relatif tertinggi di Tahura Pancoran Mas

\begin{tabular}{lc}
\hline Spesies & Dominansi Relatif (\%) \\
\hline Arenga pinnata & 30,252 \\
Elaeis guineensis & 19,413 \\
Ficus lyrata & 8,300 \\
Artocarpus elastica & 7,841 \\
Reinw. & \\
Sandoricum koetjape & 7,249 \\
Cerbera manghas & 4,071 \\
Macarangan tanarius & 3,914 \\
Microcos hirsuta-buret & 3,474 \\
Artocarpus & 3,225 \\
heterophyllus & 2,168 \\
Gigantochloa apus & \\
\hline
\end{tabular}

Tabel 7. Vegetasi dengan indeks nilai penting

\begin{tabular}{lc}
\multicolumn{2}{c}{ tertinggi di Tahura Pancoran } \\
\hline Spesies & INP \\
\hline Gigantochloa apus & 39,332 \\
Arenga pinnata & 36,609 \\
Dieffenbachia sp. & 27,122 \\
Elaeis guineensis & 21,369 \\
Selaginella doederleinii & 14,204 \\
Sandoricum koetjape & 11,650 \\
Calamus caesius & 10,882 \\
Macarangan tanarius & 10,760 \\
Epipremnum aureum & 10,276 \\
Iresine herbstii & 9,787 \\
\hline
\end{tabular}

\section{Keanekaragaman Jalan Juanda}

Jalan Juanda merupakan salah satu jalan kolektor primer yang terdapat di Kecamatan Beji dan Sukmajaya, Kota Depok. Berdasarkan
RTRW Kota Depok 2012-2032 Jalan Juanda adalah jalan kolektor primer yang menghubungkan antar pusat kegiatan wilayah dan antara pusat Kegiatan wilayah dengan pusat kegiatan lokal. Panjang jalan ini adalah 4 $\mathrm{km}$, dengan lebar tubuh jalan $14 \mathrm{~m}$, dimulai dari persimpangan Jalan Juanda-Jalan Raya Bogor sampai dengan persimpangan Jalan Juanda-Jalan Margonda. Setiap jalur masingmasing memiliki lebar $7 \mathrm{~m}$, lebar median $1 \mathrm{~m}$, dan lebar bahu jalan bervariasi [16].

Jumlah petak pada Jalan Juanda yaitu 8 petak dengan jumlah vegetasi yang terinventarisasi sebanyak 22 spesies dengan total individu 366 individu (Gambar 6). Tabel 9 menunjukkan kerapatan dan frekuensi relatif tertinggi. Spesies Hymenocallis speciosa $(26,230 \%)$, Iresine herbstii (19,672\%), Mimusops elengi $(13,388 \%)$, dan Ixora sp. (10,109\%) merupakan spesies dengan kerapatan dan frekuensi relatif tertinggi. Meskipun demikian dominansi tertinggi adalah Ficus benjamina $(94,513 \%)$ yang ditunjukkan pada tabel 10 .

Tabel 8. Vegetasi dengan indeks nilai penting terendah di Tahura Pancoran Mas

\begin{tabular}{lc}
\hline Spesies & INP \\
\hline Pseuderanthemum reticulatum & 0,489 \\
Cordyline sp. & 0,490 \\
Alocasia macorrhiza & 0,495 \\
Agathis dammara & 0,524 \\
Averrhoa carambola & 0,536 \\
Averrhoa bilimbi & 0,549 \\
Aquilaria malaccensis & 0,616 \\
Anthocephalus cinensis & 0,644 \\
Durio zibethinus & 0,709 \\
Albizia falcataria & 0,727 \\
\hline
\end{tabular}

Nilai INP tertinggi berturut-turut yaitu Ficus benjamina $(95,059)$, Hymenocallis speciosa $(52,460)$, Iresine herbstii $(39,344)$, Mimusops elengi $(26,797)$, Ixora sp. $(20,223)$, dan Samanea saman $(10,421)$ dapat dilihat pada Tabel 11. Nilai INP paling rendah di Jalan Juanda berturut-turut yaitu Chlorophytum sp. dan Pseuderanthemum reticulatum (Tabel 12). Nilai INP kedua vegetasi tersebut berturut-turut 1,093 dan 1,097. Kedua spesies ini diduga tidak mampu beradaptasi dengan baik dengan lingkungan sekitar. Nilai keanekaragaman vegetasi di Jalan Juanda masuk dalam kategori rendah dengan nilai sebesar 0,967. 
Tabel 9. Vegetasi dengan frekuensi relatif dan kerapatan relatif tertinggi di Jalan Juanda

\begin{tabular}{lrr}
\hline \multicolumn{1}{c}{ Nama spesies } & $\begin{array}{r}\text { Kerapatan } \\
\text { relatif (\%) }\end{array}$ & $\begin{array}{r}\text { Frekuensi } \\
\text { relatif (\%) }\end{array}$ \\
\hline Hymenocallis speciosa & 26,230 & 26,230 \\
Iresine herbstii & 19,672 & 19,672 \\
Mimusops elengi & 13,388 & 13,388 \\
Ixora sp. & 10,109 & 10,109 \\
Bougainvillea sp. & 5,191 & 5,191 \\
Samanea saman & 5,191 & 5,191 \\
Ipomoea batatas & 3,279 & 3,279 \\
Sansevieria trifasciata & 2,186 & 2,186 \\
Pseuderanthemum & 1,913 & 1,913 \\
reticulatum & 1,913 & 1,913 \\
Syzygium oleana & & \\
\hline
\end{tabular}

Hasil wawancara kepada 30 responden sekitar Jalan Juanda menyatakan tidak pernah terlihat satwa di area jalur hijau di Jalan Juanda. Hal ini sejalan dengan hasil data keanekaragaman vegetasi. Pada intinya ekosistem merupakan sebuah hubungan timbal balik antar komponen baik biotik maupun abiotik [17].

Tabel 10. Vegetasi dengan dominansi relatif tertinggi di Jalan Juanda

Nama spesies $\quad$ Dominansi Relatif (\%)

\begin{tabular}{ll}
\hline Ficus benjamina & 94,513 \\
Cerbera manghas & 5,405 \\
Samanea saman & 0,038 \\
Mimusops elengi & 0,021 \\
Terminalia mantaly & 0,008 \\
Muntingia calabura & 0,005 \\
Ixora sp. & 0,004 \\
Hymenocallis speciosa & 0,001 \\
Polyalthia longifolia & 0,001 \\
Bougainvillea sp. & 0,001 \\
Plumeria rubra & 0,001 \\
Agave attenuata & 0,001 \\
\hline
\end{tabular}

Rendahnya nilai keanekaragaman berhubungan dengan rendahnya temuan satwa di tapak. Terlebih pada lokasi pengambilan sangat sedikit vegetasi yang dapat mengundang kehadiran satwa. RTH di lanskap koridor sesungguhnya memiliki potensi untuk menjadi habitat satwa. Keberadaan satwa di perkotaan khususnya burung dapat menjadi indikator kualitas lingkungan yang baik [5][18][19] Disadari bahwa pemilihan vegetasi di koridor jalan memang tidak sembarangan karena memiliki beberapa kriteria yang harus dipenuhi. Keanekaragaman vegetasi memang juga tidak dapat dipaksakan namun dengan pemilihan vegetasi tertentu, dapat mengundang satwa tertentu. Selanjutnya berdasarkan hasil dari dua lokasi pengambilan data lainnya, diperoleh data vegetasi yang berpotensi untuk digunakan dalam perencanaan RTH koridor maupun taman. Vegetasi yang langka atau hampir punah juga dapat digunakan dalam perencanaan selama kriterianya menunjang persyaratan. Dengan demikian kegiatan perencanaan tidak hanya dapat mencapai tujuan estetik, tapi juga konservasi.

\begin{tabular}{lc}
\multicolumn{2}{c}{$\begin{array}{c}\text { Tabel 11. Vegetasi dengan indeks nilai penting } \\
\text { tertinggi di Jalan Juanda }\end{array}$} \\
\hline \multicolumn{1}{c}{ Nama spesies } & INP \\
\hline Ficus benjamina & 95,059 \\
Cerbera manghas & 52,460 \\
Samanea saman & 39,344 \\
Mimusops elengi & 26,797 \\
Terminalia mantaly & 20,223 \\
Muntingia calabura & 10,421 \\
Ixora sp. & 10,384 \\
Hymenocallis speciosa & 6,557 \\
Polyalthia longifolia & 5,951 \\
Bougainvillea sp. & 4,372 \\
\hline
\end{tabular}

Tabel 12. Vegetasi dengan indeks nilai penting terendah di Jalan Juanda

\begin{tabular}{|c|c|}
\hline Nama spesies & INP \\
\hline Chlorophytum sp. & 1,093 \\
\hline $\begin{array}{l}\text { Pseuderanthemum } \\
\text { reticulatum }\end{array}$ & 1,097 \\
\hline Canna sp. & 1,639 \\
\hline Ipomoea batatas & 1,639 \\
\hline $\begin{array}{l}\text { Tabernaemontana } \\
\text { divaricata }\end{array}$ & 2,186 \\
\hline Nerium oleander & 2,186 \\
\hline Sansevieria trifasciata & 2,194 \\
\hline Iresine herbstii & 2,733 \\
\hline Frucraea gigantea & 2,733 \\
\hline Syzygium oleana & 3,280 \\
\hline
\end{tabular}

\section{KESIMPULAN}

Keanekaragaman vegetasi di tiga RTH Kota Depok berada pada sebaran rendah hingga sedang. Keanekaragaman pada sebaran sedang berturut-turut ditunjukkan pada Tahura Pancoran Mas dan Taman Lembah Gurame. Selanjutnya pada Jalan Juanda, nilai keanekaragamannya rendah. Nilai keanekaragaman vegetasi memiliki hubungan 
dengan temuan satwa. Semakin tinggi nilai keanekaragaman vegetasi, semakin mudah ditemukan satwa. Patch berbentuk persegi dan irregular memiliki nilai keanekaragaman vegetasi yang tinggi dibandingkan patch berbentuk garis. Vegetasi bambu-bambuan seperti Arundinaria pumila dan Gigantochloa apus merupakan dua tanaman yang memiliki nilai penting bagi RTH di Kota Depok khususnya di Taman Lembah Gurame dan Tahura Pancoran Mas. Selanjutnya Ficus benjamina merupakan vegetasi yang memiliki nilai penting tertinggi di Jalan Juanda. Ketiga vegetasi ini dapat memberi gambaran bahwa lanskap Kota Depok sesungguhnya kaya akan air. Ketiga vegetasi ini juga menggambarkan dapat beradaptasi dengan lingkungannya di Kota Depok.

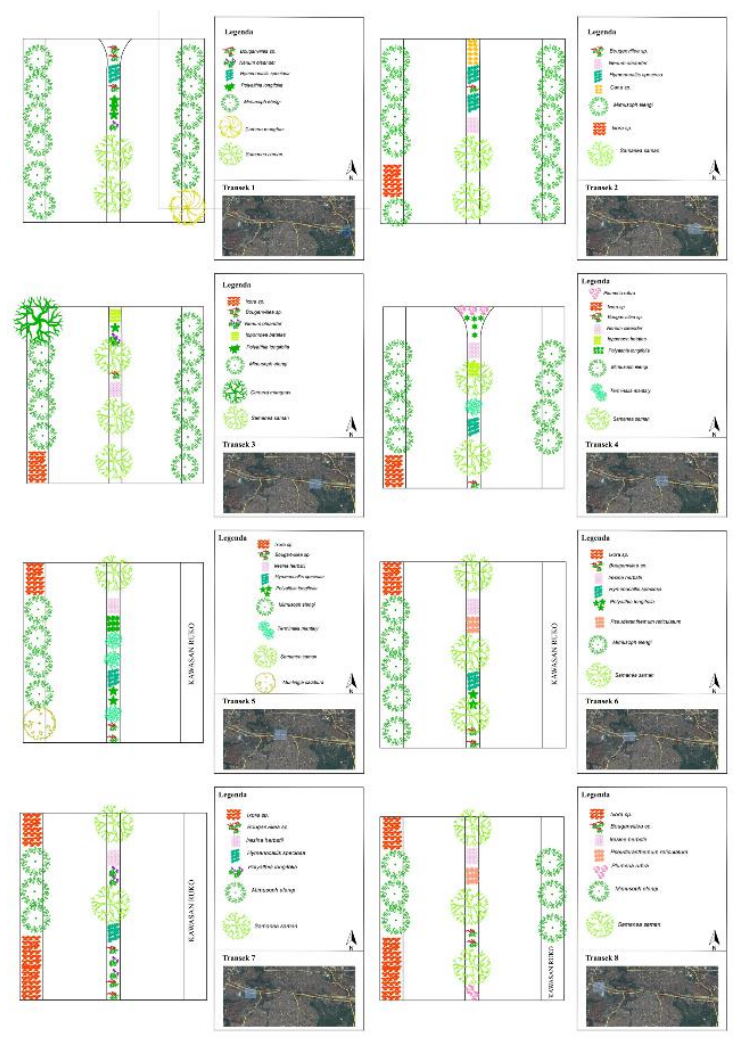

Gambar 6. Peta sebaran vegetasi pada tapak Jalan Juanda

(Sumber: Hasil Pengolahan Data, 2017)

\section{UCAPAN TERIMA KASIH}

Penelitian ini merupakan hasil kerjasama dan inisiasi dari beberapa institusi. Untuk itu penulis ingin mengucapkan terima kasih yang tulus kepada Pemerintah Daerah Kota Depok dalam hal ini Dinas Lingkungan Hidup dan Kebersihan Kota Depok, Ikatan Arsitek Lansekap Indonesia (IALI), Program Studi Arsitektur Lanskap ISTN, dan LP2M ISTN atas dukungan moral maupun materil.

\section{DAFTAR PUSTAKA}

[1] McHarg, I.L. (1971). Design with Nature. New York: History Press Doubleday \& Company Inc.

[2] Mulyandari, H. (2011). Pengantar Arsitektur Kota. Yogyakarta: Penerbit Andi.

[3] National Park Board Singapore Botanic Gardens. (2009). Trees of Our Garden City A Guide to The Common Trees of Singapore. Singapore: National Park Board Sngapore Botanic Gardens.

[4] Nurisyah, S., Pramukanto Q. (2015). Pelestarian Pohon Tua di Perkotaan. Jakarta Selatan: IALI.

[5] Nurisyah, S. (2015). Pendugaan Nilai Pohon di Kota. Jakarta Selatan: IALI.

[6] Joga, N. (2014). Greenesia. Jakarta: Gramedia.

[7] Wardiningsih, S., Syahadat, R.M., Putra, P.T., Purwati, R. Hasibuan, M.S.R. (2017). Konsep Perencanaan Tata Hijau Lanskap Sempadan Setu Mangga Bolong sebagai Area Konservasi Tumbuhan Bernilai Ekologis dan Budaya. NALAR's Jurnal Arsitektur. 16: 2: 135-144.

[8] Alfian, R., Budiarti, T., Nasrullah, N. (2016). Pengaruh Bentuk Hutan Kota terhadap Kenyamanan Termal di Sekitar Hutan Kota. Buana Sains. 16: 2: 101-110.

[9] Putrawan, I.M. (2014). Konsep-Konsep Dasar Ekologi dalam Berbagai Aktivitas Lingkungan. Bandung: Alfabeta.

[10] Dinas Kehutanan Provinsi Jawa Barat. (2016). Statistik Kehutanan Jawa Barat 2015. Bandung: Dinas Kehutanan Provinsi Jawa Barat.

[11] Mariski, Narullah, N. Gunawan, A. (2017). Persepsi dan Preferensi Pengunjung terhadap Kenyamanan Klimatologis di Taman Menteng dan Taman Kota Tebet. Jurnal Lanskap Indonesia. 9: 1: 24-35.

[12] Desyana, R.D., Muakhor, E.J., Putra, P.T. (2015). Potential of City Park in Reducing Urban Pollutants. The $5^{\text {th }}$ International Conference of Jabodetabek Study Forum Sustainable Megacities: Vulnerability, Diversity and Livability. Bogor: Crespent Press.

[13] Putra, P.T. (2011). Evaluasi Kenyamanan pada Beberapa Taman Kota di Jakarta Pusat. Bogor: IPB.

[14] Kasim, S. (2012). Nilai Penting dan Keanekaragaman Hayati Hutan Lindung Wakonti DAS Baubau. Agriplus. 22: 2: 231-240.

[15] Radnawati, D. (2005) Evaluasi Ruang Terbuka Hijau Kota Depok sebagai 
Kawasan Konservasi Air Menggunakan Data Satelit Multi Temporal. Bogor: IPB.

[16] Resunda, I. 2005. Perencanaan Lanskap Jalan Ir. H. Juanda, Kota Depok. Bogor: IPB.

[17] Irwan, Z.D. 2014. Prinsip-Prinsip Ekologi Ekosistem, Lingkungan dan Pelestariannya. Jakarta: Bumi Aksara.

[18] Sari, R.P., Wijaya, S., Munandar, A. (2013). Kajian Potensi Lanskap Jalur Kereta Rel Listrik (KRL) Bogor-Jakarta Kota sebagai Koridor Pergerakan Burung. Jurnal Lanskap Indonesia. 5: 1:17-22.

[19] Nurisyah, S. dan Mardiastuti, A. (2015). Tata Hijau Penarik Satwa Burung. Jakarta Selatan: IALI. 